\title{
Impaired Endothelial Vasomotor Function After Sirolimus-Eluting Stent Implantation
}

\author{
Soichiro Fuke, MD; Kiyoaki Maekawa, MD; Kenji Kawamoto, MD; Hironori Saito, MD; \\ Tetsuya Sato, MD; Toru Hioka, MD; Tohru Ohe, MD*
}

\begin{abstract}
Background Sirolimus inhibits endothelial cell proliferation in vitro, but although the sirolimus-eluting stent (SES) is widely used because of the very low rates of in-stent restenosis, the influence of SES on coronary endothelial vasomotor function in humans is not well known.

Methods and Results The present study included 21 patients treated with SES, and 12 patients treated with conventional bare metal stent (BMS). Endothelium-dependent vasomotor function was evaluated 6 months after stent implantation, using intracoronary acetylcholine infusion. Changes in diameter at the 5-mm proximal and distal edges of the stent, and at the control segment were assessed by quantitative coronary angiography. To evaluate native endothelial function, an intracoronary acetylcholine test was performed before stenting. In the 21 SES patients acetylcholine infusion at $10^{-8} \mathrm{~mol} / \mathrm{L}$ and $10^{-7} \mathrm{~mol} / \mathrm{L}$ produced significant vasoconstriction in the proximal stent segment $(-11.3 \pm 10.3 \%$, and $-14.1 \pm 11.3 \%$, respectively) and the distal stent segment $(-13.7 \pm 9.3 \%$, and $-17.5 \pm 12.5 \%$, respectively). In contrast, in the 12 BMS patients, acetylcholine infusion at the same concentrations did not produce a vasoconstrictive response in the proximal stent segment $(5.0 \pm 8.2 \%$ and $4.9 \pm 9.1 \%$, respectively) or the distal stent segment $(4.2 \pm 7.6 \%$ and $5.1 \pm 7.7 \%$, respectively). Intracoronary nitroglycerin induced a similar grade of vasodilation in the peri-stent area in both groups. Local endothelial function before SES implantation showed no vasoconstrictive response.

Conclusions In contrast to vasodilation in BMS patients, SES implantation in the peri-stent area resulted in a vasoconstrictive response to acetylcholine. SES implantation may impair endothelial function in humans. (Circ J 2007; 71: 220-225)
\end{abstract}

Key Words: Acetylcholine; Endothelial vasomotor function; Endothelium; Sirolimus-eluting stent

$\mathbf{T}$ he sirolimus-eluting stent (SES) is a stent coated with sirolimus, and is reported to prevent neo-intimal proliferation and injury-induced arterial intimal thickening! It is widely used to treat coronary stenotic lesions because of the associated very low rates of in-stent restenosis and need for target lesion revascularization compared with conventional bare metal stents (BMS)2-4

Sirolimus is a macrolide antifungal agent with antiproliferative and immunosuppressant properties. It inhibits vascular smooth muscle cell proliferation via cell cycle arrest in the late G1 phase 5 It also inhibits endothelial cell proliferation and smooth muscle progenitor cell circulation? Experimental studies using sirolimus 7,8 have reported a decrease in endothelial function in vitro, but the effects of SES on endothelial vasomotor function in humans is not well known? The present study aimed to evaluate the influence of SES implantation on endothelial vasomotor function 6 months following stent implantation, using a pharmacological acetylcholine test. To clarify whether endothelial dysfunction was already present before SES implantation, we examined vasomotor tone of the coronary segment

(Received May 2, 2006; revised manuscript received October 26, 2006; accepted November 6, 2006)

Department of Cardiovascular Medicine, Okayama Red Cross General Hospital, *Department of Cardiovascular Medicine, Okayama University Graduate School of Medicine, Dentistry and Pharmaceutical Sciences, Okayama, Japan

Mailing address: Soichiro Fuke, MD, Department of Cardiovascular Medicine, Okayama Redcross General Hospital, 2-1-1 Aoe, Okayama 700-8607, Japan. E-mail: fuke_s@mti.biglobe.ne.jp before stenting in a subgroup study, and compared endothelium-dependent vasomotor function before and 6 months after SES implantation.

\section{Methods}

\section{Study Population}

From August 2004 to June 2005, a total of 23 patients who had stable angina pectoris and underwent successful SES (Cypher, Cordis Corp, Miami Lakes, FL, USA) implantation were included in this study. The control group consisted of 12 patients who had significant coronary artery stenosis, and were successfully treated with BMS. Exclusion criteria were acute coronary syndrome, any coronary revascularization site, reperfused coronary arteries, stent restenosis, history of coronary spasm, symptomatic congestive heart failure, atrial fibrillation, severe valvular heart disease, previous coronary bypass graft surgery, and left main coronary artery or bifurcation lesions. Risk factors for endothelial dysfunction were assessed, and patients with insulin-dependent diabetes mellitus, hypertension (systolic blood pressure $\geq 140 \mathrm{mmHg}$ ), currently smoking, hypercholesterolemia (total cholesterol $\geq 240 \mathrm{mg} / \mathrm{dl}$ ) were also excluded. Patients in a stable condition who returned for the 6-month angiographic follow-up formed the final study population.

\section{Study Protocol}

All participants gave written informed consent for coronary angiography and the endothelial function test. The 
Table 1 Patient Characteristics and Baseline Data

\begin{tabular}{lccc}
\hline \hline & $\begin{array}{c}\text { SES group } \\
(n=21)\end{array}$ & $\begin{array}{c}\text { BMS group } \\
(n=12)\end{array}$ & p value \\
\hline Age (years) & $70 \pm 9$ & $73 \pm 9$ & 0.476 \\
Male (\%) & 91 & 75 & 0.328 \\
SBP $(\mathrm{mmHg})$ & $124 \pm 12$ & $126 \pm 14$ & 0.636 \\
DBP $(\mathrm{mmHg})$ & $70 \pm 10$ & $67 \pm 11$ & 0.422 \\
TC $(\mathrm{mg} / \mathrm{dl})$ & $187 \pm 40$ & $183 \pm 33$ & 0.733 \\
LDL-C $(\mathrm{mg} / \mathrm{dl})$ & $113 \pm 32$ & $109 \pm 26$ & 0.705 \\
Blood sugar $(\mathrm{mg} / \mathrm{dl})$ & $113 \pm 24$ & $120 \pm 29$ & 0.456 \\
Medications & & & \\
ACEI $(\%)$ & 14 & 17 & 1.000 \\
Statins $(\%)$ & 24 & 42 & 0.433 \\
Aspirin $(\%)$ & 100 & 100 & \\
\hline
\end{tabular}

SES, sirolimus-eluting stent; BMS, bare metal stent; SBP, systolic blood pressure; $D B P$, diastolic blood pressure; $T C$, total cholesterol; $L D L-C$, low-density lipoprotein-cholesterol; ACEI, angiotensin-converting enzyme inhibitors. Data are means $\pm S D$, or percentage of patients.

study was approved by the hospital's ethics committee.

Stent implantation was performed using standard techniques. Before the procedure, an intravenous heparin bolus $(100 \mathrm{IU} / \mathrm{kg})$ was administered. Glycoprotein $\mathrm{IIb} / \mathrm{III}$ inhibitors were not administered because this drug was not available in Japan. In all patients, the stent was implanted after pre-dilation procedure. The predilation site and the atherosclerotic lesions were fully coverd. Post-dilation was performed if necessary, only in the in-stent area using a quarter- or half-size up balloon. No patient required balloon dilation beyond the stent margins, avoiding balloon-induced vessel injury. Multiple stent implantations were done to cover the entire diseased segment and in such cases, a minimum overlapping portion up to $1 \mathrm{~mm}$ between stents was recommended. Multisegment or multivessel stenting was not allowed in 1 session. Complete expansion was obtained, and residual stenosis after stenting was almost $0 \%$. All patients were treated with oral aspirin $(100 \mathrm{mg} /$ day $)$ and ticlopidine $(200 \mathrm{mg} / \mathrm{day}) 2$ days before the intervention. Medications used before the intervention were continued, and did not change during the follow-up period.

\section{Coronary Vasomotor Studies 6 Months After Stent Implantation}

Coronary vasomotor function was assessed at diagnostic catheterization. Vasoactive medications, including calciumchannel blockers, nitrates, angiotensin-converting enzyme inhibitors and angiotensin-II receptor blockers, were discontinued $48 \mathrm{~h}$ before the study. To determine the baseline vasomotor response, physiologic saline was infused through the catheter, after which the endothelium-dependent vasomotor response was evaluated over a 2-min infusion of acetylcholine at 0.14 and $1.4 \mu \mathrm{g} / \mathrm{min}$, yielding estimated intracoronary concentrations of $10^{-8} \mathrm{~mol} / \mathrm{L}$ and $10^{-7} \mathrm{~mol} / \mathrm{L}$, respectively, with the assumption of a flow rate of $80 \mathrm{~mL} / \mathrm{min} !^{10}$ All infusions were delivered at a constant rate using an infusion pump. Finally, the endothelium-independent vasomotor response was evaluated after a bolus intracoronary infusion of $250 \mathrm{\mu} \mathrm{g}$ nitroglycerin. Angiography was repeated immediately after each infusion. A 3-min period was allowed to elapse between each drug infusion. Arterial blood pressure, heart rate, 12-lead electrocardiogram were continuously monitored during the study.

\section{Endothelial Function Before Stent Implantation}

Endothelial dysfunction may already be present before
Table 2 Baseline Angiographic Data

\begin{tabular}{lccc}
\hline \hline & $\begin{array}{c}\text { SES group } \\
(n=21)\end{array}$ & $\begin{array}{c}\text { BMS group } \\
(n=12)\end{array}$ & p value \\
\hline Site of lesion & & & \\
$\quad$ LAD/LCX/RCA & $11 / 3 / 7$ & $5 / 2 / 5$ & 0.837 \\
Stent number & $1.19 \pm 0.60$ & $1.08 \pm 0.29$ & 0.568 \\
Stent length $(\mathrm{mm})$ & $23.9 \pm 14.2$ & $20.0 \pm 11.1$ & 0.420 \\
Stent diameter $(\mathrm{mm})$ & $3.00 \pm 0.42$ & $3.33 \pm 0.54$ & 0.056 \\
\hline
\end{tabular}

$L A D$, left anterior descending artery; $L C X$, left circumflex artery; $R C A$, right coronary artery. Other abbreviations see in Table 1.

Data are means $\pm S D$, or number.

stent implantation. Therefore, we examined the vasomotor tone of the coronary segment where stent implantation was planned in 10 randomly selected patients from the SES group and 5 patients from the BMS group. After 6 months, endothelial vasomotor function was re-evaluated, and compared with the baseline. The endothelium-dependent vasomotor response was evaluated using acetylcholine with the same method to assess native coronary endothelial function before stenting, as well as by intracoronary nitroglycerin.

\section{Quantitative Coronary Angiography}

Quantitative coronary angiography was performed from 2 orthogonal projections that well delineated the coronary artery of interest, without overlapping of side branches and with less foreshortening, using the Philips quantitative coronary analysis system (Philips Medical, The Netherlands). Measurements were performed by a blinded independent observer. Coronary artery diameter was calculated at the stent edge (approximately $5 \mathrm{~mm}$ proximal and distal of the stent edges). Another angiographically normal segment was selected in a non-stented coronary artery, and changes in diameter were assessed. Measurement of coronary diameter before stenting was performed at the site where stent implantation was planned. The same segments were identified by anatomical landmarks, and assessed at each measurement. An average of 3 measurements was obtained in each setting. Mean luminal diameter was averaged for 2 projections. Stenosis was considered significant if there was $>75 \%$ lumen diameter narrowing in at least 1 projection.

\section{Statistical Analysis}

Data are reported as means \pm standard deviation. Comparisons within groups were carried out by analysis of variance for repeated measurements. When the test was significant, Bonferroni tests for paired comparisons were used. For intergroup comparisons, a paired or unpaired Student's t-test was applied. Categorical variables were analyzed by the chi-square test and Fisher's exact test. A p-value of $<0.05$ was considered to be statistically significant. All statistical analyses were performed using a personal computer with the statistical package SPSS for Windows (SPSS Inc, Chicago, IL, USA).

Interobserver and intraobserver variabilities for quantitative coronary angiography measurements were assessed in 8 randomly selected patients.

\section{Results}

No major adverse cardiac events occurred during the follow-up period, including death, myocardial infarction, and target lesion revascularization. One patient in the SES 


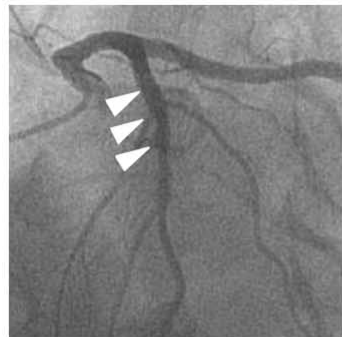

Saline

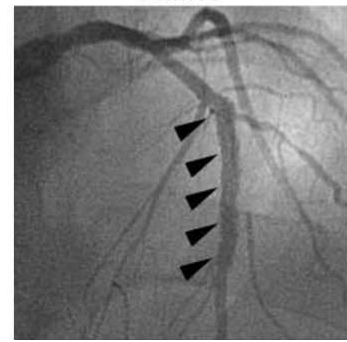

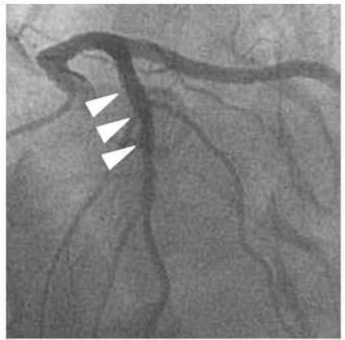

Ach $10^{-8} \mathrm{~mol} / \mathrm{L}$

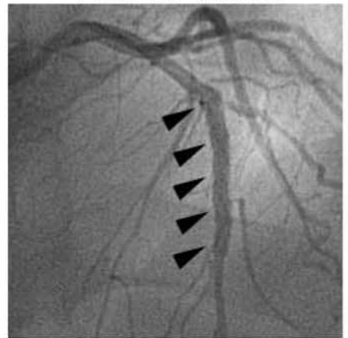

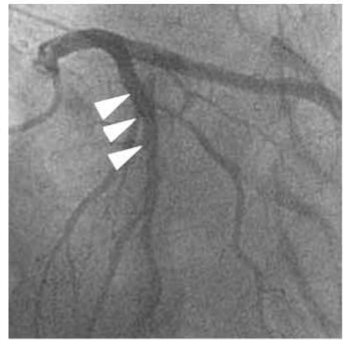

Ach $10^{-7} \mathrm{~mol} / \mathrm{L}$

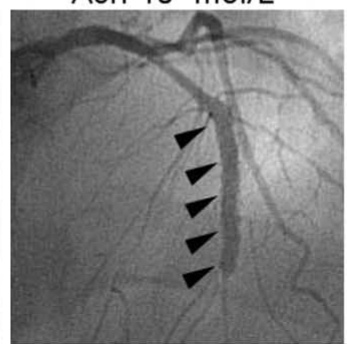

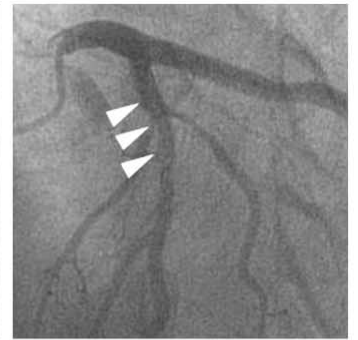

NTG

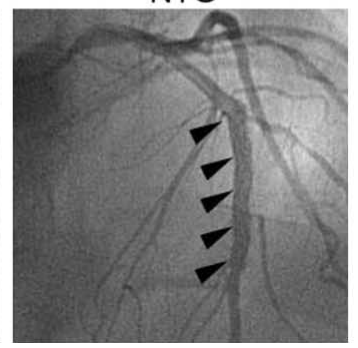

Fig 1. Typical responses induced by acetylcholine (Ach) and nitroglycerin (NTG) infusion 6 months after implantation in patients with bare metal stents (BMS) or sirolimus-eluting stents (SES). (Upper column) BMS (white arrows) in the left anterior oblique view; (Lower column) SES (black arrows) in the straight view. Vasocontriction was induced by acetylcholine infusion in the peri-stent segments after SES but not BMS, implantation. Saline, physiologic saline.

Table 3 Changes in Coronary Luminal Diameter With Intracoronary Acetylcholine and Nitroglycerin, 6 Months After Stent Implantation

\begin{tabular}{lll}
\hline \hline & $\begin{array}{c}\text { SES group } \\
(n=21)\end{array}$ & $\begin{array}{c}\text { BMS group } \\
(n=12)\end{array}$ \\
\hline Proximal stent segment diameter $(\mathrm{mm})$ & & \\
$\quad$ Saline & $2.35 \pm 0.49$ & $2.57 \pm 0.47$ \\
Acetylcholine $10^{-8} \mathrm{~mol} / \mathrm{L}$ & $2.10 \pm 0.60^{*}$ & $2.67 \pm 0.33$ \\
Acetylcholine $10^{-7} \mathrm{~mol} / \mathrm{L}$ & $2.04 \pm 0.59^{*}$ & $2.66 \pm 0.33$ \\
Nitroglycerin & $2.65 \pm 0.54^{*}$ & $2.89 \pm 0.39^{*}$ \\
Intra-stent segment diameter $(\mathrm{mm})$ & & \\
Saline & $2.64 \pm 0.59$ & $2.70 \pm 0.46$ \\
Acetylcholine $10^{-8} \mathrm{~mol} / \mathrm{L}$ & $2.59 \pm 0.60$ & $2.72 \pm 0.46$ \\
Acetylcholine $10^{-7} \mathrm{~mol} / \mathrm{L}$ & $2.61 \pm 0.61$ & $2.73 \pm 0.42$ \\
Nitroglycerin & $2.70 \pm 0.61$ & $2.78 \pm 0.40$ \\
Distal stent segment diameter $(\mathrm{mm})$ & & \\
Saline & $2.27 \pm 0.79$ & $2.29 \pm 0.48$ \\
Acetylcholine $10^{-8} \mathrm{~mol} / \mathrm{L}$ & $1.95 \pm 0.69^{*}$ & $2.39 \pm 0.53$ \\
Acetylcholine $10^{-7} \mathrm{~mol} / \mathrm{L}$ & $1.89 \pm 0.78^{*}$ & $2.39 \pm 0.47$ \\
Nitroglycerin & $2.38 \pm 0.76$ & $2.56 \pm 0.60^{*}$ \\
Control segment diameter $(\mathrm{mm})$ & & \\
Saline & $2.42 \pm 0.67$ & $2.79 \pm 0.40$ \\
Acetylcholine $10^{-8} \mathrm{~mol} / \mathrm{L}$ & $2.47 \pm 0.63$ & $2.85 \pm 0.40$ \\
Acetylcholine $10^{-7} \mathrm{~mol} / \mathrm{L}$ & $2.41 \pm 0.70$ & $2.82 \pm 0.41$ \\
Nitroglycerin & $2.65 \pm 0.56^{*}$ & $3.04 \pm 0.49 *$ \\
\hline
\end{tabular}

Saline, physiologic saline. Other abbreviations see in Table 1.

Data are means $\pm S D .{ }^{*} p<0.05$ vs saline.

group refused follow-up angiography and another patient in the SES group was excluded because of severe vasospastic angina during the follow-up period. No patients in either group showed angiographic restenosis. Therefore, the final study population comprised 21 patients in the SES group, and 12 patients in the BMS group. Stents used in the BMS group were 3 Multilink stents (Guidant Corp, Indianapolis, IN, USA), 6 Driver stents (Medtronic Inc, Minneapolis, MN, USA), 2 S670 stents (Medtronic Inc), and 1 BX Velocity stent (Cordis Corp, Miami Lakes, FL, USA). In the SES group, 1 stent was used in 19 patients, and 3 stents were implanted in 2 patients. In the BMS group, 1 was used in 11 patients, and 2 stents were used in 1 patient. Stent length was slightly longer in the SES group than in the BMS group; however, the difference was not statistically significant.

Baseline patient characteristics and angiographic data were similar between the 2 groups (Tables 1,2). Assessment of endothelial function was conducted $6 \pm 1$ months after stent implantation.

\section{Coronary Vasomotor Response 6 Months After Stent Implantation}

No significant changes in mean aortic pressure and heart rate were observed in either group during acetylcholine infusion. Fig 1 shows the typical responses in BMS and SES patients induced by acetylcholine and nitroglycerin infusion 6 months after implantation. Quantitative coronary angiography data in the stent, proximal stent segment, distal stent segment, and control segments are presented in Table 3.

In the SES group (Fig 2), acetylcholine infusion at $10^{-8} \mathrm{~mol} / \mathrm{L}$ and $10^{-7} \mathrm{~mol} / \mathrm{L}$ produced significant vasoconstriction in the distal stent segment $(-13.7 \pm 9.3 \%, \mathrm{p}=0.001$ and $-17.5 \pm 12.5 \%, \mathrm{p}=0.001$; vs saline, respectively) and proximal stent segment $(-11.3 \pm 10.3 \%, \mathrm{p}=0.001$ and $-14.1 \pm$ $11.3 \%, \mathrm{p}=0.001$; vs saline, respectively) compared with the control segment $(2.7 \pm 5.3 \%, \mathrm{p}=0.195$ and $-0.3 \pm 10.2 \%$, $\mathrm{p}=1.0$; vs saline, respectively). In contrast, in the BMS group (Fig 3), acetylcholine infusion produced no coronary vasoconstriction in the distal stent segment $(4.2 \pm 7.6 \%$, $\mathrm{p}=0.474$, and $5.1 \pm 7.7 \%, \mathrm{p}=0.262$; vs saline, respectively), proximal stent segment $(5.0 \pm 8.2 \%, \mathrm{p}=0.355$, and $4.9 \pm 9.1 \%$, $\mathrm{p}=0.522$; vs saline, respectively), or control segment $(2.2 \pm$ $3.0 \%, \mathrm{p}=0.164$, and $1.5 \pm 7.6 \%, \mathrm{p}=1.0$; vs saline, respectively). There were no significant changes in diameter induced by acetylcholine in the stented segment in either the SES or BMS group. Intracoronary nitroglycerin induced a similar grade of vasodilation in both groups.

\section{Comparison of Vasomotor Function Before and 6 Months After Stent Implantation}

Before SES implantation, no coronary vasoconstriction 

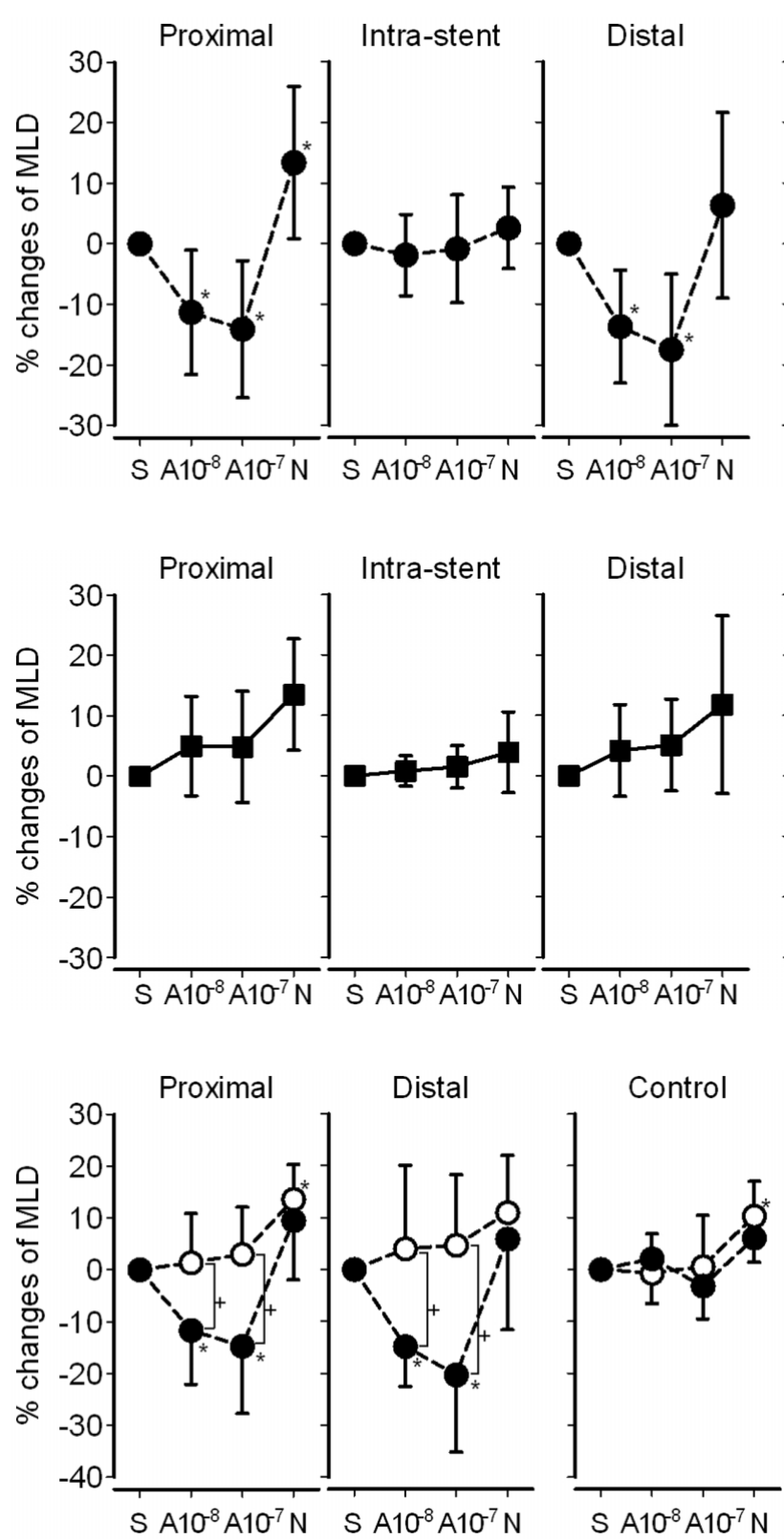

Fig 4. Changes in vasomotor function before and 6 months after sirolimus-eluting stent implantation. Panel shows percent changes in coronary luminal diameter in each segment. ( $\bigcirc)$ Percent diameter changes before sirolimus-eluting stent implantation; $(\bullet)$ results after 6 months. A, acetylcholine; MLD, mean luminal diameter; N, nitroglycerin; S, physiologic saline. ${ }^{*} \mathrm{p}<0.05$ vs saline, ${ }^{+} \mathrm{p}<0.05$ between each group.

was observed at the proximal and distal sites where stent implantation was planned, with doses of acetylcholine at $10^{-8} \mathrm{~mol} / \mathrm{L}$ and $10^{-7} \mathrm{~mol} / \mathrm{L}$ (Fig 4). After 6 months, acetylcholine produced significant vasoconstriction of the distal stent segment $(-14.8 \pm 7.7 \%, \mathrm{p}=0.006$ and $-20.3 \pm 14.9 \%$, $\mathrm{p}=0.001$; vs baseline, respectively) and of the proximal stent segment $(-11.7 \pm 10.4 \%, \mathrm{p}=0.011$ and $-14.7 \pm 13.0 \%$, $\mathrm{p}=0.001$; vs baseline, respectively).

In the BMS group (Fig 5), coronary vasoconstriction was not observed before or after stent implantation.

\section{Observer Variabilities}

Inter- and intraobserver variabilities for quantitative
Control

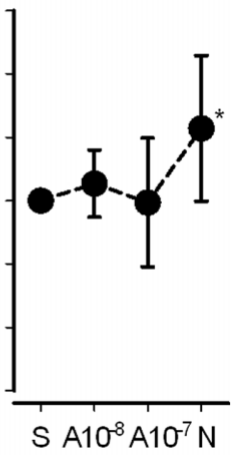

Control

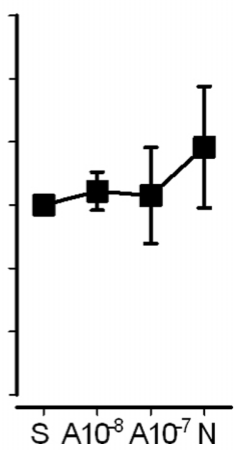

Fig 2. Changes in coronary luminal diameter of each segment (expressed in percentages) 6 months after sirolimus-eluting stent implantation. A, acetylcholine; MLD, mean luminal diameter; N, nitroglycerin; $\mathrm{S}$, physiologic saline. ${ }^{*} \mathrm{p}<0.05$ vs saline.
Fig 3. Changes in coronary luminal diameter of each segment (expressed in percentages) 6 months after bare metal stent implantation. A, acetylcholine; MLD, mean luminal diameter; $\mathrm{N}$, nitroglycerin; $\mathrm{S}$, physiologic saline. ${ }^{*} \mathrm{p}<0.05$ vs saline.

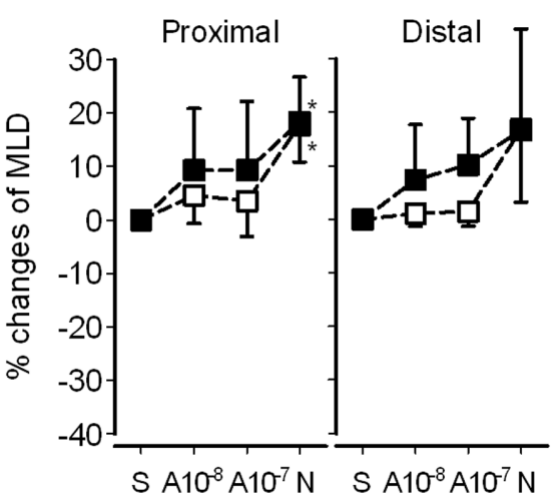

Fig 5. Changes in vasomotor function before and 6 months after bare metal stent implantation. Panel shows percent changes in coronary luminal diameter in each segment. ( $\square$ ) Percent diameter changes before bare metal stent implantation; (ם) results after 6 months. A, acetylcholine; MLD, mean luminal diameter; N, nitroglycerin; S, physiologic saline. ${ }^{*} \mathrm{p}<0.05$ vs saline.

measurements of coronary angiography were $0.06 \mathrm{~mm}$ and $0.01 \mathrm{~mm}$, respectively.

\section{Discussion}

Our results indicate that SES implantation impaired acetylcholine-induced coronary artery vasodilation of the proximal and distal stent segments 6 months after SES implantation, whereas the BMS showed no significant vasoconstrictive response. Acetylcholine did not produce a vasoconstrictive response before SES implantation. The vasodilative response to nitroglycerin was preserved in both groups. 
Acetylcholine dilates normal coronary artery segments by promoting the synthesis and release of nitric oxide in the endothelium (endothelium-derived nitric oxide) 11 In contrast, in segments where endothelial damage is present, acetylcholine constricts coronary arteries because of disturbed nitric oxide synthesis and release 12 Therefore, the present results suggest impairment of local endothelial function by SES implantation in human coronary arteries.

\section{Endothelial Function After BMS Implantation}

Enhanced endothelial dysfunction following conventional BMS implantation has been reported ${ }^{13,14}$ Caramori et al used acetylcholine to demonstrate long-term endothelial dysfunction after BMS implantation in human coronary arteries 14 whereas in our study, there was not a significant vasoconstrictive response at the peri-stent area with BMS. The different vasoconstrictive responses between these 2 studies may be, in part, related to the acetylcholine concentration. Caramori et al used 3 concentrations $\left(10^{-6} \mathrm{~mol} / \mathrm{L}\right.$, $10^{-5} \mathrm{~mol} / \mathrm{L}$, and $10^{-4} \mathrm{~mol} / \mathrm{L}$ ) and a vasoconstrictive response was only observed at the maximum concentration of $10^{-4} \mathrm{~mol} / \mathrm{L}$, whereas we used $10^{-8} \mathrm{~mol} / \mathrm{L}$ and $10^{-7} \mathrm{~mol} / \mathrm{L}$ acetylcholine, which are more diluted concentrations, and in the peri-stent area of SES implantation, a vasoconstrictive response to these relatively small doses of acetylcholine was observed.

\section{Endothelial Function After SES Implantation}

Sirolimus has itself been reported to inhibit endothelial function in vitro. Mohacsi et al reported that sirolimus inhibited growth factor-induced proliferation of cultured endothelial and smooth muscle cells, and Jeanmart et al ${ }^{8}$ also showed endothelial dysfunction in porcine coronary arteries with an in vitro model of drug incubation in Krebsbicarbonate solution. They reported that porcine epicardial coronary arteries exposed to sirolimus had severe impairment of the relaxation response to serotonin (an agonist that binds to 5-HT1D receptors coupled Gi-protein) and bradykinin (an agonist that binds to $\mathrm{B}_{2}$ receptors coupled Gq-protein), and they discussed the possibility of sirolimus having a direct negative effect on endothelial function.

In a porcine model, $\mathrm{Yu}$ et $\mathrm{al}^{15}$ reported that the distribution of sirolimus from a SES immediately localized in tissue, with approximately $88-90 \%$ in the coronary artery surrounding the stent structure and 6-7\% in the heart. Although they used a high-dose sirolimus copolymer containing about $170 \mathrm{mg} / \mathrm{cm}^{2}$ (Cypher; $\left.140 \mathrm{mg} / \mathrm{cm}^{2}\right)$, the indication was that SES influences not only the site at which the strut contacts, but also the coronary artery surrounding the stent structure and indeed the whole body. Such pharmacokinetics may explain why vasoconstriction occurs in the peri-SES area.

Fukuda et al $^{6}$ also reported that sirolimus had an inhibitory effect on circulating smooth muscle progenitor cells in humans. In the present study, the vasoconstriction in the proximal SES segment induced by acetylcholine infusion supports their result.

Maekawa et al reported a case of vasospastic angina in a Japanese man after SES implantation ${ }^{16}$ and Hofma et al ${ }^{17}$ reported similar findings to ours in a smaller group; that is, significant vasoconstriction in SES but not BMS patients after acetylcholine infusion at 6 month follow-up. However, they only examined vasoconstriction in distal stent segments after SES implantation and whether vasoconstriction had existed before SES implantation was not clarified.
Togni et $\mathrm{al}^{9}$ evaluated endothelial function using flowmediated changes induced by exercise, and reported that exercise-induced coronary vasodilation was impaired in the peri-stent area of SES patients. They also reported that BMS implantation did not impair exercise-induced coronary artery vasodilation in the peri-stent area 18 Although a direct comparison of endothelial function tests using acetylcholine and exercise-induced flow changes is difficult, our results for both SES and BMS groups are consistent with those of Togni et al.

In humans, partial re-endothelialization has been documented 3 weeks after Cypher stent use ${ }^{19,20}$ Coated sirolimus is gradually eluted from the stent strut, with the Cypher stent designed to have more than $80 \%$ of sirolimus eluted by 30 days ${ }^{3,21}$ and to be fully eluted by 60 days ${ }^{22}$ Therefore, endothelial dysfunction 6 months after the SES implantation was not due to the direct effect of sirolimus. However, it might be possible that the impairment of endothelial function is caused directly by sirolimus in the early phase of SES implantation is sustained for 6 months. A lack of complete endothelial coverage with implanted SES has been reported in autopsied cases, ${ }^{23,24}$ and from angioscopic imaging. 25 A possible explanation of our results involves decreased endothelial nitric oxide synthesis because of the sustained direct influence of sirolimus from the early phase on G-protein-mediated vasorelaxation and inadequate endothelial coverage, which would lead to a vasoconstrictive response to acetylcholine in the peri-stent area.

\section{Study Limitations}

First, although baseline characteristics were similar between the 2 groups, patients were not randomized to receive either SES or BMS. Second, our subjects included patients receiving statins ${ }^{26}$ and angiotensin-converting enzyme inhibitors.7 Although these drugs may improve endothelial function, their effects are still controversial ${ }^{28}$ and the usage was similar between the 2 groups. Third, although the platform for the Cypher stent in the SES group was a BX Velocity stent, we did not always use that type of stent in the BMS group, but these differences may have had minimal effects unless the stent strut design and material were different from a Cypher stent. Fourth, our study ended 6 months after SES implantation; thus whether peri-SES endothelial dysfunction persists beyond 6 months remains unknown. Finally, although the endothelial responses in our groups of patients were uniform in both groups, there were only a few patients enrolled, thus limiting the statistical power of the study results.

\section{Conclusions}

SES implantation produced an acetylcholine-induced coronary vasoconstrictive response at the proximal and distal stent segments, whereas BMS showed no significant vasoconstrictive response. These results suggest that the SES impairs endothelial function in humans.

\section{References}

1. Sousa JE, Costa MA, Abizaid A, Abizaid AS, Feres F, Pinto IM, et al. Lack of neointimal proliferation after implantation of sirolimuscoated stents in human coronary arteries: A quantitative coronary angioplasty and three-dimensional intravascular ultrasound study. Circulation 2001; 103: 192-195.

2. Moses JW, Leon MB, Popma JJ, Fitzgerald PJ, Holmes DR, O'Shaughnessy C, et al for the SIRIUS Investigators. Sirolimuseluting stents versus standard stents in patients with stenosis in a 
native coronary artery. $N$ Engl J Med 2003; 349: 1315-1323.

3. Morice MC, Serruys PW, Sousa JE, Jean Fajadet J, Ban Hayashi E, Perin M, et al; RAVEL Study Group. A randomized comparison of a sirolimus-eluting stent with a standard stent for coronary revascularization. N Engl J Med 2002; 346: 1773-1780.

4. Nakamura M, Wada M, Hara H, Kozuma K, Otsuka Y, Miyazaki S. Angiographic and clinical outcomes of a pharmacokinetic study of sirolimus-eluting stents: Lesson from restenosis cases. Circ J 2005; 69: $1196-1201$

5. Marx SO, Jayaraman T, Go LO, Marks AR. Rapamycin-FKBP inhibits cell cycle regulators of proliferation in vascular smooth muscle cells. Circ Res 1995; 76: 412-417.

6. Fukuda D, Sata M, Tanaka K, Nagai R. Potent inhibitory effect of sirolimus on circulating vascular progenitor cells. Circulation 2005; 111: 926-931.

7. Mohacsi PJ, Tuller D, Hulliger B, Wijngaard PLJ. Different inhibitory effects of immunosuppressive drugs on human and rat aortic smooth muscle and endothelial cell proliferation stimulated by platelet-derived growth factor or endothelial cell grouth factor. J Heart Lung Transplant 1997; 16: 484-492.

8. Jeanmart H, Malo O, Carrier M, Nickner C, Desjardins N, Perrault LP. Comparative study of cyclosporine and tacrolimus vs newer immunosuppressants mycophenolate mofetil and rapamycin on coronary endothelial function. J Heart Lung Transplant 2002; 21: $990-$ 998.

9. Togni M, Windecker S, Cocchia R, Wenaweser P, Cook S, Billinger $\mathrm{M}$, et al. Sirolimus-eluting stents associated with paradoxic coronary vasoconstriction. J Am Coll Cardiol 2005; 46: 231 - 236.

10. Vita JA, Yeung AC, Winniford M, Hodgson JM, Treasure CB, Klein $\mathrm{JL}$, et al. Effect of cholesterol-lowering therapy on coronary endothelial vasomotor function in patients with coronary artery disease. Circulation 2000; 102: 846-851.

11. Takase B, Hamabe A, Satomura K, Akima T, Uehata A, Matsui T, et al. Comparable prognostic value of vasodilator response to acetylcholine in brachial and coronary arteries for predicting long-term cardiovascular events in suspected coronary artery disease. Circ $J$ 2006; 70: 49-56.

12. Ludmer PL, Selwyn AP, Shook TL, Wayne RR, Mudge GH, Alexander RW, et al. Paradoxical vasoconstriction induced by acetylcholine in atherosclerotic coronary arteries. $N$ Engl $J$ Med 1986; 315: 1046-1051.

13. Van Beusekom HM, Whelan DM, Hofma SH, Krabbendam SC, van Hinsbergh VW, Verdouw PD, et al. Long-term endothelial dysfunction is more pronounced after stenting than after balloon angioplasty in porcine coronary arteries. J Am Coll Cardiol 1998; 32: 11091117.

14. Caramori PR, Lima VC, Seidelin PH, Newton GE, Parker JD, Adelman AG. Long-term endothelial dysfunction after coronary artery stenting. J Am Coll Cardiol 1999; 34: 1675-1679.
15. Yu MY, Gao RL, Jiang J, Cheng SJ, Yuan JQ, Wang CN, et al. Pharmacokinetics of rapamycin-eluting stents in miniswine coronary model. Chin Med J 2004; 117: 1459-1463.

16. Maekawa K, Kawamoto K, Fuke S, Yoshioka R, Saito H, Sato T, et al. Severe endothelial dysfunction after sirolimus-eluting stent implantation. Circulation 2006; 113: e850-e851.

17. Hofma SH, van der Giessen WJ, van Dalen BM, Lemos PA, McFadden EP, Sianos G, et al. Indication of long-term endothelial dysfunction after sirolimus-eluting stent implantation. Eur Heart $J$ 2006; 27: 166-170.

18. Maier W, Windecker S, Kung A, Lutolf R, Eberli FR, Meier B, et al. Exercise-induced coronary artery vasodilatation is not impaired by stent placement. Circulation 2002; 105: 2373-2377.

19. Farb A, Sangiorgi G, Carter AJ, Walley VM, Edwards WD, Robert S, et al. Pathology of acute and chronic coronary stenting in humans. Circulation 1999; 99: 44-52.

20. Grewe PH, Deneke T, Machraoui A, Barmeyer J, Muller K-M. Acute and chronic tissue response to coronary stent implantation: Pathologic findings in human specimen. J Am Coll Cardiol 2000; 35: 157-163.

21. Klugherz BD, Llanos G, Lieuallen W, Kopia GA, Papandreou G, Narayan P, et al. Twenty-eight-day efficacy and pharmacokinetics of the sirolimus-eluting stent. Coron Artery Dis 2002; 13: 183-188.

22. Virmani R, Guagliumi G, Farb A, Musumeci G, Grieco N, Motta T, et al. Localized hypersensitivity and late coronary thrombosis secondary to a sirolimus-eluting stent: Should we be cautious? Circulation 2004; 109: 701-705.

23. Guagliumi G, Farb A, Musumeci G, Valsecchi O, Tespili M, Motta T, et al. Sirolimus-eluting stent implanted in human coronary artery for 16 months: Pathological findings. Circulation 2003; 107: 13401341.

24. Sousa JE, Costa MA, Farb A, Abizaid A, Sousa A, Seixas AC, et al. Images in cardiovascular medicine: Vascular healing 4 years after the implantation of sirolimus-eluting stent in humans: A histopathological examination. Circulation 2004; 110: e5-e6.

25. Kotani J, Awata M, Nanto S, Uematsu M, Oshima F, Minamiguchi $\mathrm{H}$, et al. Incomplete neointimal coverage of sirolimus-eluting stents: Angioscopic findings. J Am Coll Cardiol 2006; 47: 2108-2111.

26. Egashira K, Hirooka Y, Kai H, Sugimachi M, Suzuki S, Inou T, et al. Reduction in serum cholesterol with pravastatin improves endothelium-dependent coronary vasomotion in patients with hypercholesterolemia. Circulation 1994; 89: 2519-2524.

27. Mancini GB. Long-term use of angiotensin-converting enzyme inhibitors to modify endothelial dysfunction: A review of clinical investigations. Clin Invest Med 2000; 23: 144-161.

28. Vita JA, Yeung AC, Winniford M, Hodgson JM, Treasure CB, Klein $\mathrm{JL}$, et al. Effect of cholesterol-lowering therapy on coronary endothelial vasomotor function in patients with coronary artery disease. Circulation 2000; 102: 846-851. 